\title{
Factors Influencing Teenager to Initiate Smoking in South-west Bangladesh
}

\author{
Akil Hossain ${ }^{1}$, Quazi Zahangir Hossain ${ }^{1}$, Qazi Azad-uz-zaman ${ }^{2, *}$, Farzana Rahman ${ }^{3}$ \\ ${ }^{1}$ Environmental Science Discipline, Life Science School, Khulna University, Khulna, Bangladesh \\ ${ }^{2}$ Research \& Development Section, Japan Association of Drainage and Environment, Bangladesh \\ ${ }^{3}$ Research \& Development Section, Bangladesh Center for Communication Programs, Bangladesh
}

Copyright (C) 2015 by authors, all rights reserved. Authors agree that this article remains permanently open access under the terms of the Creative Commons Attribution License 4.0 International License

\begin{abstract}
Long term smoking poses many health hazards that most of the teenagers know, but many do not care. Once they start smoking, struggle to cease throughout the lifespan. Peer pressure is one of the main causes of initiating smoking observed by many studies. The research was mainly carried out to explore the factors influencing the teen to initiate smoking in south-west region of Bangladesh. A number of 408 students from level 7 to 12 were interviewed using a semi-structured questionnaire during February to November, 2014. The curiosity of the teen and 'to get rid of frustration' is the two main reasons of initiating smoking. Some other acknowledged reasons are peer pressure; desire to fit with friends, fun making, copying parent or elderly, and to relief from mental stress. More than half of the teens smoke to overcome psychological stress. Some others are smoking to keep relaxed from study load, to keep away family problem as well as for outlook and personality. Many of the teen smokers used to smoke because of reasonably priced and easy to obtain. To overcome the situation, academic institutes can arrange workshop or seminar regarding the consequences of smoking on health. Health effects of smoking can also be added in the curriculum so that the teen can understand and re-think about their harmful habit.
\end{abstract}

Keywords Teenager, Initiation, Smoking, Influencing Factors

\section{Introduction}

Section 2(d) defined smoking as inhaling and exhaling the smoke of any tobacco product and shall include the holding of or controlling any ignited tobacco product [1]. A report of CDC (2011) revealed that concurrent use of multiple tobacco products is prevalent among youth [2]. Greece is a leading tobacco-producer country within European Union. In Greece the prevalence of smoking is $37 \%$ and the annual per capita consumption of cigarettes was one of the highest in the
European Union [3, 4]. Global age-standardized prevalence of daily tobacco smoking was $31.1 \%$ in 2012 for men [5]. Research on tobacco use and socio-demographic issues was conducted from school students of 10 to 12 years in Bihar, India [6]. Given the importance of tobacco as a risk to health, monitoring the distribution and intensity of tobacco use is critical particularly for low- and middle- income countries. Bangladesh is a low-income country and one of the largest tobacco consuming countries in the world [5]. With a population of 150 million, Bangladesh is one of the top ten countries in the world having a high smoking prevalence, where over 22 million adults smoke [7].

Adolescent smoking is a global issue because there is not a single country around the world where the teens are not smoking [8]. Many adult smokers initiate the smoking habit during adolescence or as young adults [9]. 10.4\% were current cigarette smoking among 13 to 15 years old [10]. American Psychological Association (2014) reported that non-depressed teens who smoked in the prior month faced approximately a four times greater risk of developing depression than non-smoking teens [11]. WHO stated that the current smoking prevalence of girls is $2 \%$, about $13.2 \%$ never smokers expressed their willingness to initiate smoking within the next one year [12]. Between the ages of 14 to 18 years a person is most likely to attract towards the smoking habit and become an addict for the rest of his or her life. This age represents the growth of maturity where the teens make choices for their life style and plan where they want to see themselves in the future. This is the age where the inspiration is at the maximum level and adolescents are more conscious of their personality, styles and making up their role models. Different factors like stress, attention disorder, psychological pressures and conflicts from parents play an important role in impacting the individual personality and most of the teens are seen fighting with these kind of problems due to lack of parental interest or sometime over protectiveness of parents [13].

Tobacco use is the leading cause of preventable death and disease worldwide and is estimated to kill more than 5 
million people each year [14]. Tobacco smoking is a leading modifiable global disease risk factor, with nearly 6 million premature deaths, $6.90 \%$ of years of life lost and $5.5 \%$ disability-adjusted life-years (DALYs) in 2010 [15, 16]. Tobacco use in adolescents has been called a "pediatric epidemic" because of increasing level of its use and dire public health implications [17]. Tobacco is a leading cause of illness in the developed world where non-communicable diseases contribute to the greatest burden of disease [18]. Much of the severe health consequences of smoking are in adulthood. However, there are also significant short and intermediate term effects of smoking that may be experienced such as asthma and chronic cough $[19,20]$. Information on adolescent smoking is valuable not just because smoking is independently associated with adverse health effects, but also through the clustering of other harmful lifestyles among adolescents who smoke [21]. According to Centers for Disease Control and Prevention (CDC) in 2011 stated that the teen smoking still affects 54\% of high school students and one in three who start smoking as a teen will die later of smoking related causes [22]. Smoking among adolescents is a major concern because long term smoking poses many health hazards. Most of all adolescents know the long term effects of smoking are and many do not care, because they are not concerned with what might happen to them forty or fifty years down the road [8]. If smoking continues at the current rate among youth 5.6 million of today's Americans younger than 18 will die early from a smoking-related illness [23].

American Journal of Public Health (2002) described that youths ages 12 to 17 were less inclined to see smoking as harmful and reported an increased likelihood to smoke after they had viewed a television advertisement urging parents to speak to their children about not smoking [24]. Giving teen's information about the risks of smoking and chewing tobacco, and establishing clear rules can help protect them from these unhealthy habits [25]. Public health strategies to combat tobacco-induced illnesses have aimed at reducing uptake and promoting smoking cessation. Given the limitations of population-based programs to reduce smoking initiation among the public [26], the need to provide cessation support to those who continue to smoke is substantial. Therefore, identification of factors that could facilitate cessation is important in the design of evidence-based smoking cessation interventions. A report published in 2013 revealed that the teens who start smoking will likely struggle to break the habit throughout their entire lives, making preventing teen smoking even more vital. According to the report, 9 out of 10 smokers pick up the habit before they turn 18 years of age [27]. Mayo Foundation for Medical Education and Research in 2012 mentioned many ways to keep the teens smoke-free and suggested that if the teen has already started smoking, avoid threats and ultimatums. Instead, find out why the teen is smoking and discuss ways to help the teen quit [28]. This high rate of tobacco-attributable mortality underscores the rapidly growing health and economic burden of tobacco use in Bangladesh. To address this growing epidemic of tobacco-induced deaths, there is an urgent need to reduce tobacco use in Bangladesh which will require curtailing initiation of tobacco use and promotion of smoking cessation [29]. There is no or scanty study has been found relating to the teen smoking in Khulna areas. In these circumstances, it is good to know the prevalence of the teen smoking rate and how they are being involved in smoking under different socio-demographic conditions. The study was carried out to explore the prevalence of teen smoking as well as influencing factors to initiate smoking in south-west areas of Bangladesh.

\section{Materials and Methods}

A cross sectional study was done among students of 13 to 19 years old in south-west, Bangladesh during February to November, 2014.

\subsection{Sample Size Determination}

The formula mentioned below has been used for sample size $n$ determination with $95 \%$ confidence considering an interval of $5[30]$.

$$
\mathrm{n}=\frac{\mathrm{z}_{\alpha / 2}^{2}}{\mathrm{~d}^{2}} \mathrm{pq}
$$

Where, $n=$ sample size, $p=$ proportion, $\mathrm{q}=1-\mathrm{p}, d=$ deviation $=0.05, z_{\propto / 2}=1.96,1-\propto=0.95$. Here, $\mathrm{p}=0.23$ (approximate proportion of initiating smoking before teenage). So the sample size, $\mathrm{n}=(1.96)^{2} \times 0.23 \times 0.77 /(.05)^{2}=$ $272.1 \approx 272$

But, due to heterogeneity in urban and rural area, design effect, 1.5 had been considered. Here, total sample size, $\mathrm{n}=$ $272 \times 1.5=408$ is considered.

\subsection{Data Collection}

The research intends to investigate the differences between urban and rural areas. All the suitable schools and colleges were listed up and details were collected. A total of 12 schools and colleges had been selected based on convenient condition of which 6 from urban and 6 from rural areas. The number of institutions was limited to 12 because of limitation of resources. A total of 191 teen was surveyed from Khulna and Bagerhat sadar considered as urban area; and 217 teen were surveyed from Rupsha upazila under Khulna district and Fakirhat upazila under Bagerhat district were considered as a rural area.

After getting permission from the authority, frame of students was constructed from the registrar book. Some cases senior students come first of the list and vice-versa on other cases. From each institution, 34 students were expected to respond. The respondents were selected by systematic random sampling technique. The selected units were excluded if absent at the institutes during the survey or unwilling to respond. In some cases alternative respondents 
were interviewed following circular systematic sampling technique, where applicable. Semi-structured questionnaire was used, that was prepared and pre-tested in the field before the survey team was deployed to the field for data collection.

Since the respondents were young boys and girls, the data collectors were asked to clarify all the doubts of them during data collection. They were also asked strictly to avoid using mobile phone and camera to take photos of the respondents as well as to behave politely with due respect. The research team confirmed almost no chance of physical, social, and psychological risk for the respondent as well as invasion to them and their privacy. We also avoided the topics carefully that can create discomfort to the respondents.

Informed consent was obtained from each respondent verbally prior to the beginning of the survey. The respondents were requested to provide relevant information and were filled up questionnaire in front of them. They were assured that they will not be compelled to answer all of the questions as well as right to withdraw even after the response. They were also guaranteed that the information from them to be used for specific research only with due confidentiality.

\subsection{Data Analysis}

Comparative analysis, dividing respondents into different groups was done to meet the objective of the study. Microsoft Excel and SPSS (version 16.0) were used to perform the analysis. Bivariate analysis was done using Chi-square test. For the statistical tests, a 'p' value of $<=0.05$ was considered statistically significant.

Table 1. Social-demographic Status of Respondents between Urban and Rural Institute

\begin{tabular}{|c|c|c|c|c|}
\hline \multirow{2}{*}{ Variables } & \multirow{2}{*}{ Category } & \multicolumn{3}{|c|}{ Residence of the respondent } \\
\hline & & Urban n (\%) & Rural n (\%) & Total n (\%) \\
\hline \multirow{3}{*}{ Gender } & Female & $81(19.8)$ & $65(15.9)$ & $146(35.7)$ \\
\hline & Male & $110(27.0)$ & $152(37.3)$ & $262(64.3)$ \\
\hline & Total & $191(46.8)$ & $217(53.2)$ & $408(100)$ \\
\hline \multirow{2}{*}{ Education } & Secondary & $94(23.0)$ & $128(31.4)$ & $222(54.4)$ \\
\hline & Higher secondary & $97(23.8)$ & $89(18.1)$ & $186(45.6)$ \\
\hline \multirow{2}{*}{ Living with whom } & With family & $174(42.6)$ & $205(50.2)$ & $379(92.8)$ \\
\hline & Without family & $17(4.2)$ & $12(3.0)$ & $29(7.2)$ \\
\hline \multirow{3}{*}{ Father's education } & Illiterate & $8(2.0)$ & $23(5.6)$ & $31(7.6)$ \\
\hline & Formal education & $181(44.4)$ & $191(46.8)$ & $372(91.2)$ \\
\hline & Non-formal schooling & $2(0.4)$ & $3(0.8)$ & $5(1.2)$ \\
\hline \multirow{5}{*}{ Father's occupation } & Government service & $46(11.8)$ & $44(10.8)$ & $90(22.6)$ \\
\hline & Non-government service & $25(6.0)$ & $17(4.2)$ & $42(10.2)$ \\
\hline & Business & $82(20.0)$ & $91(22.3)$ & $173(42.3)$ \\
\hline & Retired & $5(1.2)$ & $7(1.7)$ & $12(2.9)$ \\
\hline & Others & $32(7.8)$ & $58(14.2)$ & $90(22.0)$ \\
\hline \multirow{3}{*}{ Mother's education } & Illiterate & $6(1.4)$ & $24(6.0)$ & $30(7.4)$ \\
\hline & Formal education & $183(44.9)$ & $192(47.0)$ & $375(91.9)$ \\
\hline & Non-formal schooling & $2(0.5)$ & $1(0.2)$ & $3(0.7)$ \\
\hline \multirow{6}{*}{ Mother's occupation } & Government service & $14(3.4)$ & $6(1.5)$ & $20(4.9)$ \\
\hline & Non-government service & $4(1.0)$ & $9(2.2)$ & $13(3.2)$ \\
\hline & Business & $2(0.5)$ & $4(1.0)$ & $6(1.5)$ \\
\hline & Retired & $1(0.2)$ & $0(0)$ & $1(0.2)$ \\
\hline & Housewife & $166(40.7)$ & $193(47.3)$ & $359(88.0)$ \\
\hline & Others & $4(1.0)$ & $5(1.2)$ & $9(2.2)$ \\
\hline \multirow{6}{*}{ Monthly family income } & $<10000$ & $29(7.1)$ & $41(10.0)$ & $70(17.1)$ \\
\hline & $10001-20000$ & $70(17.1)$ & $78(19.1)$ & $148(36.2)$ \\
\hline & 20001-30000 & $48(11.8)$ & $65(16.0)$ & $113(27.8)$ \\
\hline & $30001-40000$ & $19(4.6)$ & $12(3.0)$ & $31(7.6)$ \\
\hline & $40001-50000$ & $9(2.2)$ & $10(2.4)$ & $19(4.6)$ \\
\hline & $>50000$ & $16(4.0)$ & $11(2.7)$ & $26(6.7)$ \\
\hline
\end{tabular}




\section{Results}

\subsection{Socio-demographic Feature}

Gender, education, living arrangement, education, and occupation of the respondent's parents and their monthly family income are shown in Table 1.

Among the respondents, 35.7\% and 64.3\% were girls and boys, respectively from urban $(46.8 \%)$ and rural $(53.2 \%)$ areas. Among the respondents, $54.4 \%$ and $45.6 \%$ was at secondary and higher secondary level respectively. Although the distribution is similar between urban and rural areas, 92.8\% were living with their families and rest $7.1 \%$ was living apart from family. More than $90 \%$ of the parents (91.9\% mother and $91.2 \%$ father) had formal education.

Considering the occupation of the respondent's father, $42.3 \%$ were businessman followed by government service $(22.0 \%)$, non-government services $(10.2 \%)$, and $22.1 \%$ had other occupations. The mothers were mostly house wife $(88.0 \%)$, followed by government services $(4.9 \%)$, non-government services $(3.2 \%)$, businesses $(1.5 \%)$, retired from service $(0.2 \%)$ other occupations $(2.2 \%)$. More than half $(53.3 \%)$ of the respondent's monthly family income was less than BDT 20,000 (US\$ 256.4, US\$ $1=78$ BDT), $27.8 \%$ between BDT 20,001 to 30,000 and $18.9 \%$ were more than BDT 30,000. Peoples having higher income were more likely to live in urban areas compared to rural.

\subsection{Distribution of Teen Smoker and Associated Factors}

Table 2 shows the prevalence of smoking and factors having the possibility of contribution to initiate smoking. About $15.7 \%(n=64)$ of the respondents were found smoker and mostly male (14.5\%). In rural areas institutes, smokers are twice in number $(10.6 \%)$ compared to that of urban areas (5.1\%). Among the smokers, $4.9 \%$ and $10.8 \%$ were the students from secondary (level 7 to 10) and higher secondary (level 11 to 12) school, respectively.

Around $14.2 \%$ teen smokers were living with family and the remaining $1.5 \%$ apart from family. The living arrangement of the teen is independent of smoking behaviour $(\mathrm{p}=0.442)$. About $13.2 \%$ smokers had a personal income while $2.5 \%$ didn't have which is also insignificantly associated $(p=0.490)$ and $15.2 \%$ teen smokers used to get monthly pocket money from their parents while only $0.5 \%$ was not get a significant association with use of smoking tobacco $(\mathrm{p}=0.013)$. No one from $42.7 \%$ respondents' family was used to smoke while one or more persons from the remaining 56.3\% respondents' family were used to smoke. Use of smoking tobacco by the teen is found to have significant association with family member's smoking habit. Again $13.7 \%$ of the teen smokers had smoker friends, which are highly significantly associated with $\mathrm{p}<0.0001$.

Table 2. Prevalence of Smoking and Factors Contributed to Initiate

\begin{tabular}{|c|c|c|c|c|c|}
\hline \multirow{2}{*}{ Variables } & \multirow{2}{*}{ Category } & \multicolumn{3}{|c|}{ Use of smoking tobacco } & \multirow{2}{*}{ p-value } \\
\hline & & No n $(\%)$ & Yes n $(\%)$ & Total n (\%) & \\
\hline \multirow{2}{*}{ Gender of the respondent } & Female & $141(34.6)$ & $5(1.2)$ & $146(36.8)$ & \\
\hline & Male & $203(49.7)$ & $59(14.5)$ & $262(62.2)$ & \\
\hline \multirow{2}{*}{$\begin{array}{l}\text { Residence of the } \\
\text { respondent }\end{array}$} & Urban & $170(41.7)$ & $21(5.1)$ & $191(46.8)$ & \\
\hline & Rural & $174(42.6)$ & $43(10.6)$ & $217(53.2)$ & \\
\hline \multirow{2}{*}{$\begin{array}{l}\text { Education of the } \\
\text { respondent }\end{array}$} & Secondary & $202(49.5)$ & $20(4.9)$ & $222(54.4)$ & \\
\hline & Higher secondary & $142(34.8)$ & $44(10.8)$ & $186(45.6)$ & \\
\hline \multirow{2}{*}{ Living with whom } & With family & $321(78.7)$ & $58(14.2)$ & 379 (92.9) & \multirow{2}{*}{0.442} \\
\hline & Without family & $23(5.6)$ & $6(1.5)$ & $29(7.1)$ & \\
\hline \multirow{2}{*}{ Have personal income } & No & $306(75.0)$ & $54(13.2)$ & $360(88.2)$ & \multirow{2}{*}{0.490} \\
\hline & Yes & $38(9.3)$ & $10(2.5)$ & $47(11.8)$ & \\
\hline \multirow{2}{*}{ Get pocket money } & No & $50(12.2)$ & $2(0.5)$ & $52(12.7)$ & \multirow{2}{*}{0.013} \\
\hline & Yes & $294(72.1)$ & $62(15.2)$ & $356(87.3)$ & \\
\hline \multirow{2}{*}{ Family member smoke } & No & $155(38.0)$ & $19(4.7)$ & $174(42.7)$ & \multirow{2}{*}{0.010} \\
\hline & Yes & $189(46.3)$ & $45(11.0)$ & $234(56.3)$ & \\
\hline \multirow{2}{*}{ Friends smoke } & No & $218(53.4)$ & $8(2.0)$ & $226(55.4)$ & \multirow{2}{*}{0.000} \\
\hline & Yes & $126(30.9)$ & $56(13.7)$ & $182(44.6)$ & \\
\hline
\end{tabular}


Table 3. Age of Initiation and How to Collect

\begin{tabular}{|c|c|c|c|c|}
\hline \multirow{2}{*}{ Variables } & \multirow{2}{*}{ Category } & \multicolumn{3}{|c|}{ Residence of the respondent } \\
\hline & & Urban n (\%) & Rural n (\%) & Total n (\%) \\
\hline \multirow{4}{*}{$\begin{array}{l}\text { Age of trying first } \\
\text { cigarette }\end{array}$} & $\geq 12$ & $7(18.4)$ & $3(7.9)$ & $10(26.3)$ \\
\hline & $13-15$ & $5(13.2)$ & $6(15.8)$ & $11(28.9)$ \\
\hline & $16-18$ & $8(21.0)$ & $8(21.0)$ & $16(42.1)$ \\
\hline & $\geq 19$ & $1(2.6)$ & $0(0.0)$ & $1(2.6)$ \\
\hline \multirow{4}{*}{$\begin{array}{l}\text { Age of becoming } \\
\text { regular smokers }\end{array}$} & $\geq 12$ & $5(15.6)$ & $1(3.1)$ & $6(18.8)$ \\
\hline & $13-15$ & $4(12.5)$ & $4(12.5)$ & $8(25.0)$ \\
\hline & $16-18$ & $8(25.0)$ & $8(25.0)$ & $16(50.0)$ \\
\hline & $\geq 19$ & $2(6.25)$ & $0(0.0)$ & $2(6.25)$ \\
\hline \multirow{5}{*}{$\begin{array}{c}\text { Number of } \\
\text { cigarette/bidi } \\
\text { smoked on average } \\
\text { per day }\end{array}$} & $<1 /$ day & $4(10.5)$ & $4(10.5)$ & $8(21.0)$ \\
\hline & $1 /$ day & $1(2.6)$ & $3(7.9)$ & $4(10.5)$ \\
\hline & $2-5 /$ day & $6(15.8)$ & $6(15.8)$ & $12(31.6)$ \\
\hline & $6-10$ & $6(15.8)$ & $3(7.9)$ & $9(23.7)$ \\
\hline & $>10$ & $4(10.5)$ & $1(2.6)$ & $5(13.2)$ \\
\hline \multirow{4}{*}{ Way to get cigarettes } & I buy from the store & $19(50.0)$ & $10(26.3)$ & $29(76.3)$ \\
\hline & Someone else gives money to buy & $1(2.6)$ & $0(0.0)$ & $1(2.6)$ \\
\hline & Someone else gives them to me & $1(2.6)$ & $6(15.8)$ & $7(18.4)$ \\
\hline & Others & $0(0.0)$ & $1(2.6)$ & $1(2.6)$ \\
\hline \multirow{3}{*}{ Place of smoking } & At home & $1(2.6)$ & $0(0.0)$ & $1(2.6)$ \\
\hline & At school/college inside premises & $2(5.3)$ & $1(2.6)$ & $3(7.9)$ \\
\hline & At school/college outside premises & $18(47.4)$ & $16(42.1)$ & $34(89.5)$ \\
\hline
\end{tabular}

\subsection{Age of Initiation and How to Collect}

Table 3 is showing age of initiation and how to collect tobacco products. Among smokers $(n=64), 71.0 \%$ tried their first cigarette at the age between 13 to 18 years, more specifically $42.1 \%$ tried their first cigarette at the age between 16 to 18 years, and $28.9 \%$ tried between 13 to 15 years. Most alarming scenario was 26.3\% (urban $18.4 \%$, rural $7.9 \%)$ tried their first cigarette before teenage $(\leq 12)$. No one in rural areas tried first cigarette after 18 years. Overall $75.0 \%$ became regular smokers at the age between 13 to 18 years while about $18.8 \%$ (urban $15.6 \%$, rural $3.1 \%$ ) become regular smoker before teenage $(\leq 12)$.

Around $31.6 \%$ (urban $15.8 \%$, rural $15.8 \%$ ) of the teenage smokers used to take 2 to 5 cigarette/bidi, 23.7\% (urban $15.8 \%$, rural $7.9 \%$ ) used to take 6 to 10 , and $13.2 \%$ (urban $10.5 \%$, rural $2.6 \%$ ) used to take more than 10 stick every day. About $21.0 \%$ used to take cigarette less than daily. The large number of teen smokers (overall 76.3\%, urban 50.0\%, rural $26.3 \%$ ) buy cigarette by themselves from the store. Most of the teen smokers (overall $89.5 \%$, urban $47.4 \%$, rural $42.1 \%$ ) used to smoke at around school/collage and some of them (7.9\%) were smoking inside school/college premises.

\subsection{Reason of Teens to Initiate Smoking}

The respondents $(n=58)$ were asked about the reasons for initiating smoking. They acknowledged a variety of reasons for initiation of smoking (Table 4). Curiosity of teenagers $(48.3 \%)$ and to get rid of frustration $(34.5 \%)$ was recognized by the teen as the two main causes of initiating smoking. Some other causes identified were peer pressure $(24.1 \%)$, desire to fit with friends $(20.7 \%)$, for fun $(10.4 \%)$, copying parent or elderly who smoke $(8.6 \%)$, and also to relief from mental stress $(6.9 \%)$. 
Table 4. The Causes behind the Initiation of Smoking among Teenagers (Multiple Responses)

\begin{tabular}{|c|c|}
\hline Causes of smoking initiation & Percentage (\%) \\
\hline Get rid of frustration & 34.5 \\
\hline Curiosity & 48.3 \\
\hline Peer pressure & 24.1 \\
\hline Copying parents, elderly who smoke & 8.6 \\
\hline Desire to fit with friends & 20.7 \\
\hline For fun & 10.4 \\
\hline Mental stress & 6.9 \\
\hline
\end{tabular}

Table 5 shows the causes of smoking continuation among teenagers dividing into urban and rural area. More than half $(51.7 \%)$ of the teen smokers claimed that they smoke to overcome psychological stress, control anger which is insignificantly associated with residence of the respondents ( $\mathrm{p}=0.284$ ), $22.4 \%$ used to smoke to keep themselves relaxed from study load $(\mathrm{p}=0.046$, significantly associated with residence), $17.2 \%$ used to smoke as inspiration, for outlook and personality $(\mathrm{p}=0.570$, insignificant), and $13.8 \%$ used to smoke to keep themselves away from family problem ( $\mathrm{p}=0.978$, insignificant). More than half $(51.7 \%$ ) used to smoke as easy to obtain ( $\mathrm{p}=0.737$, insignificant), and $78.1 \%$ used to smoke as affordably priced ( $\mathrm{p}=0.737$, insignificant).

Table 5. Causes of Smoking Continuation among Teenagers

\begin{tabular}{|c|c|c|c|c|c|}
\hline \multirow{2}{*}{ Variables } & \multirow{2}{*}{ Category } & \multicolumn{4}{|c|}{ Residence of the respondent } \\
\hline & & Urban n (\%) & Rural n (\%) & Total n $(\%)$ & p-value \\
\hline \multirow{2}{*}{ Smoke to overcome psychological stress, control anger } & No & $9(15.5)$ & $19(32.8)$ & $28(48.3)$ & \multirow{2}{*}{0.284} \\
\hline & Yes & $13(22.4)$ & $17(29.3)$ & $30(51.7)$ & \\
\hline \multirow{2}{*}{ Smoking as inspiration, for outlook and personality } & No & $19(32.8)$ & $29(50.0)$ & $48(82.8)$ & \multirow{2}{*}{0.570} \\
\hline & Yes & $3(5.2)$ & $7(12.1)$ & $10(17.2)$ & \\
\hline \multirow{2}{*}{ Smoke keeps relaxed from study load } & No & $14(24.1)$ & $31(53.4)$ & $45(77.6)$ & \multirow{2}{*}{0.046} \\
\hline & Yes & $8(13.8)$ & $5(8.6)$ & $13(22.4)$ & \\
\hline \multirow{2}{*}{ Smoke keeps away you from family problem } & No & $19(32.8)$ & $31(53.4)$ & $50(86.2)$ & \multirow{2}{*}{0.978} \\
\hline & Yes & $3(5.2)$ & $5(8.6)$ & $8(13.8)$ & \\
\hline \multirow{2}{*}{ Smoke as easy to obtain } & No & $10(17.2)$ & $18(31.0)$ & $28(48.3)$ & \multirow{2}{*}{0.737} \\
\hline & Yes & $12(20.7)$ & $18(31.0)$ & $30(51.7)$ & \\
\hline \multirow{2}{*}{$\begin{array}{l}\text { Smoke as affordably priced } \\
\text { (*I manage it) }\end{array}$} & No* & $9(14.1)$ & $5(7.8)$ & 14 (21.9) & \multirow{2}{*}{0.066} \\
\hline & Yes & $19(29.7)$ & $31(48.4)$ & $50(78.1)$ & \\
\hline
\end{tabular}

\section{Discussion}

About $15.7 \%(\mathrm{n}=64)$ of the respondents were found smoker and mostly male (14.5\%) found by the present study. However, Hublet et al. (2006) have reported that female adolescents have higher prevalence of cigarette smoking than males in Sweden (13.7\% vs. 5.5\%), Norway (19.9\% vs. $15.4 \%$ ), Austria (24.7\% vs. $19.5 \%$ ), Belgium (19.0 vs. $16.8 \%$ ) and Finland (18.0 vs. a16.4). Furthermore, it's of considerable interest that in some countries (e.g. Greece, Japan, Malawi and Ethiopia) apparently smoking is more prevalent among adolescent boys than girls [31].

The CDC report opined that the teen smoking is down since $1990 \mathrm{~s}$, the problem has remained relatively stable throughout the 2000s. Still the teen smoking affects $54.0 \%$ of high school students, and one in three who start smoking as a the teen will die later of smoking related causes [22]. The percentage is much higher than the result $(15.7 \%)$ of present study. Although the rate (urban $5.1 \%$, rural $10.6 \%$ ) is not same, similar result is found by another study which shows the smoking rate in rural areas is slightly higher $(23.6 \%)$ than in urban areas (21.3\%) [32].

A study shows that livings with family members or friends have been associated with smoking in adolescents and young adults. Smoking mother increases the chances of smoking in students however, the difference between two groups was 
not statistically significant $(\mathrm{p}>0.05)$. Surprisingly, having smoker father is significantly $(\mathrm{p}=0.004)$ associated with smoking in college students [33].

Present study found about $13.2 \%$ smokers had personal income while $2.5 \%$ didn't have which was insignificantly associated $(p=0.490)$ but $15.2 \%$ the teen smokers used to get monthly pocket money from their parents which has significant association with use of smoking tobacco $(p=0.013)$. Mohan et al have also reported on a four times the risk of being a smoker among adolescents who received pocket money versus none in India [34]. Another study also shows the similar results that pocket money was associated with increased odds of smoking. Compared to boys who reported having seven Euro or less per week, those who had more 32 Euro or more were more than six times likely to smoke. For girls, those who had more than 32 Euro per week were more than 10 times likely to smoke than those who had seven Euro or less [35].

Students who have smokers' siblings have greater chances of becoming smoker than those students who have non smoker siblings. Students who have smoker friends are seven times at risk of initiating smoking, than those who have non-smoker friends [33]. Present study found differently as the living arrangement of the teen is independent of smoking behavior but similarity observed in case of significant association with family member's smoking. Again this study shows $13.7 \%$ of the teen smokers had smoker friends which was highly significantly associated with $p<0.0001$ [36]. Students at the age range of 19 to 21 , and those who had smoker father, smoker siblings and smoker friends were more likely to smoke cigarette $(p<0.05)$ [33]. An extensive research conducted at Italy in 2002 indicated that $27.8 \%$ prevalence among the offspring's of smoking parents, and it varied from $7.2 \%$ among the children at the age of 12 to $61 \%$ in adolescents of 17 years. Results showed that children of smoker parents are different than children of non-smoker parents towards their first exposures to cigarettes [36]. Teacher's use of tobacco was also positively associated with current use of tobacco among students $[37,38]$. Of the students, $74.1 \%$ mentioned that there was at least one smoking person in their household and $43.3 \%$ declared that they were exposed to second-hand smoking at home [39]. A research with 6141 adolescents (51.5\% males, $48.5 \%$ females) shows that cigarette smoking was associated with male gender, parental smoking, and having pocket money $\geq 16$ Euros [34]. Boys with only father smoking were more likely to smoke than those who had non-smoking fathers. Likewise, girls with only mother smoking were more likely to smoke than those with non-smoking mothers [35]. Students whose friends are smokers were 5 times more likely to smoke compared to those whose friends are non-smokers. Those students having fathers with no formal schooling were more likely to smoke as compared to those whose fathers had some degree of education. Students having non-working mothers were more likely to smoke as compared to students with working mothers [40]. Subjects whose parents had higher school education or higher were less likely to smoke than those whose parents had elementary education or less [35].

Present research shows age between 16 to 18 years is most likely to try the first cigarette. Between the age group of 14 to 18 years a person is most likely to attract towards the smoking habit and become an addict for the rest of his or her life [13]. Almost 4 in a 10 students (38.6\%) smoked their first cigarette before age 10 [12] is higher (26.3\%) than the present research. The median age of the first smoking experience was 9.5 years while the youngest age for the first smoking experience was seven [36]. GYTS reported, in Bihar $58.9 \%$ current use of any tobacco product (male $61.4 \%$, female $51.2 \%$ ); $13.7 \%$ current smoking tobacco use among students aged 13 to 15 years. Over $60 \%$ of ever users reported initiation at the age of 10 years or earlier [41]. As Kids Health reports, 9 out of 10 smokers pick up the habit before they turn 18 years [27]. The survey found that $23.0 \%$ of adult aged 15 years or above currently smoke tobacco in Bangladesh (males 44.7\%, females 1.5\%) [32]. Everyday, almost 3900 adolescents under 18 years of age try their first cigarette. More than 950 of them will become daily smoker [42].

Overall $75.0 \%$ became regular smoker at the age between 13 to 18 years while about $18.8 \%$ become before $\leq 12$ years in present study. Nearly 3 of every 100 middle school students $(2.5 \%)$ reported in 2014 that they smoked cigarettes in the past 30 days -a decrease from $4.3 \%$ in 2011 [43]. About 9 of every 100 high school students $(9.2 \%)$ reported in 2014 that they smoked cigarettes in the past 30 days -a decrease from $15.8 \%$ in 2011 [43]. Among 269 ever users $29.2 \%$ have initiated from class 3 when they were approximately 8 years old [44]. The GATS (2009) in Bangladesh found that $23.0 \%$ of adult age of 15 years or above is currently smoke tobacco, of them $1.5 \%$ and $44.7 \%$ female and male, respectively [32]. Each day in the United States, more than 3,200 people younger than 18 years of age smoke their first cigarette, and an estimated 2,100 youth and young adults who have been occasional smokers become daily cigarette smokers $[45,46]$.

Present study showed that the teen smokers mainly buy cigarette by themselves from the store. Another study shows that among ever users, almost half had received their first tobacco from friends [44]. It shows that various psychological and social factors are related like stress, domestic problems, and other issues lead the start of smoking [13]. One of the main causes for teenage smoking is peer pressure [42]. A research work conducted in 2011 to find out the reasons of the teen smoking revealed that many teenagers may think that smoking looks cool, and they may choose to begin smoking in order to fit with their friends [47]. Sixty students who had smoked at least once indicated the following reasons for this experience: $63.3 \% \quad(n=38)$ curiosity, $15 \%(\mathrm{n}=9)$ imitation, $10 \%(\mathrm{n}=6)$ friends' influence, $10 \%(\mathrm{n}=6)$ social environment influence, $6.67 \%(\mathrm{n}=4)$ influence of advertisements, $3.33 \%(\mathrm{n}=2)$ someone smoking 
at home, $3.33 \%(\mathrm{n}=2)$ influence of movies [39]. About $62.3 \%$ students initiate smoking at or before 16 year of age, and peer pressure $69.2 \%$ was the main reason for initiation of smoking, other reasons for initiation of smoking in students were pleasure $15.1 \%$, stress $10 \%$, and curiosity $5.7 \%$. About $56 \%$ students smoked at least 10 cigarettes a day, $32.7 \%$ smoked 11 to 20 , and $11.30 \%$ smoked $>20$ cigarette per day. Type of college, living area, smoker mother and anxious behaviours are not associated with cigarette smoking in college students $(\mathrm{P}>0.05)$ [33]. The study also showed peer pressure $(24.1 \%)$ was one of the main reasons for the teen to initiate smoking but the two main reasons obtained by the research are curiosity $(48.3 \%)$ and get rid of frustration $(34.5 \%)$.

\section{Conclusions and Recommendations}

Smoking is a form of drug and teenage is most likely to attract towards the smoking habit and become an addict for the rest of his or her life. The research result documented that peer pressure, bad companion, curiosity, desire to fit with friends, get rid of frustration, copying parents or elders are the main causes of initiation smoking among the teen.

School can arrange some workshop or seminar regarding the consequences of smoking on health. Effects of smoking can also be added in the curriculum and teachers can deliver lectures on that issue, so the teen can re-think about the habit. The research will help to find out the causes of smoking initiation to the specific areas that can direct the different ways to keep the teen smoke free. Further research can also be done to make the results more reliable or on some other related issues in southwest region as well as in Bangladesh.

\section{Acknowledgements}

The Authors wish to express gratefulness and thanks to the Bangladesh Center for Communication Programs (BCCP) and Institute for Global Tobacco Control (IGTC) based on the Johns Hopkins Bloomberg School of Public Health for financial support to carry out the research.

\section{Ethical Approval}

The study received ethical clearance from Bangladesh Medical Research Council (BMRC), BMRC Bhaban, Mohakhali, Dhaka-1212, Bangladesh.

\section{REFERENCES}

[1] Bangladesh. Smoking and Tobacco Products Usage (Control) Act, Unofficial Translation, 2005, p. 7, online available from http://www.tobaccolabels.ca/legislat/bangladesh
[2] CDC. Youth and Tobacco Use, 2011, online available from http://www.cdc.gov/tobacco/data_statistics/fact_sheets/youth _data/tobacco_use/

[3] World Health Organization: Competing the Tobacco Epidemic. The World Health Report 1999. Geneva1999.

[4] House of Lords: Select Committee on European Communities. 30th Report. Tobacco Production in the European Community, online available from http://www.parliament.uk

[5] M. Ng, M. K. Freeman, T. D. Fleming, M. Robinson, L. Dwyer-Lindgren, et al. Smoking Prevalence and Cigarette Consumption in 187 Countries, 1980-2012. JAMA, Vol.311, pp.183-192. 2014.

[6] G. Singh, D. N. Sinha, P. S. Sarma \& K. R. Thankappan. Prevalence and Correlates of Tobacco Use among 10-12 Year Old School Students in Patna District, Bihar, India. Indian Pediatrics, Vol.42. August17, 2005.

[7] WHO. 2009. Global Adult Tobacco Survey (GATS): Bangladesh. World Health Organization. online available from:

http://www.searo.who.int/LinkFiles/Regional Tobacco_Surv eillance_System_GATSBAN_FullReport2009.pdf

[8] Cedu.niu.edu. Adolescent Smoking, 2014, online available from http://www.cedu.niu.edu/ shumow/iit/

[9] J. MacKey \& M. Ericksen. Tobacco Atlas. World Health Organization (WHO). 2002.

[10] A. Kyrlesi, E. S. Soteriades, C. W. Warren, J. Kremastinou, P. Papastergiou, N. R. Jones \& C. Hadjichristodolou. Tobacco Use among Students Aged 13-15 Years in Greece: the GYTS project. BMC Public Health, Vol.7, No.3. 2007.

[11] D. Smith. Smoking Increases Teen Depression, American Psychological Association. 2014, online available from http://www.apa.org/monitor/dec00/smoking.aspx

[12] WHO. Report on Global Youth Tobacco Survey (GYTS) and Global School Personnel Survey (GSPS) in Bangladesh, Regional Office for South-East Asia, New Delhi. 2007.

[13] F. Khurshid \& U. Ansari. Causes of Smoking Habit among the Teenagers. Interdisciplinary Journal Contemporary Research of Business, Vol.3, No.9, pp.848-855. 2012.

[14] World Health Organization (WHO). WHO Report on the Global Tobacco Epidemic, 2008. The MPOWER Package. Geneva, Switzerland: World Health Organization. 2008, online available from http://www.who.int/tobacco/mpower/mpower_report_full_2 008.pdf.

[15] S. S. Lim, T. Vos, A. D. Flaxman, G. Danaei, K. Shibuya, et al. A Comparative Risk Assessment of Burden of Disease and Injury Attributable to 67 Risk Factors and Risk Factor Clusters in 21 Regions, 1990-2010: A Systematic Analysis for the Global Burden of Disease Study 2010. Lancet, Vol.380, pp.2224-2260. 2012.

[16] Evaluation IfHMa. Global Burden of Disease (GBD) Visualizations.

[17] C. L. Perry, M. P. Eriksen \& G. Giovino. Tobacco Use: A Paediatric Epidemic. Tobacco Control, Vol.3, pp.97-98. 1994.

[18] C. D. Mathers \& D. Loncar. Projections of Global Mortality 
and Burden of Disease from 2002 to 2030. PLoS Med, Vol.3, No.11, pp.442. 2006.

[19] M. D. Eisner \& C. Iribarren. The Influence of Cigarette Smoking on Adult Asthma Outcomes. Nicotine Tob Res, Vol.9, No.1, pp.53-56. 2007.

[20] S. K. Jindal, A. N. Aggarwal, K. Chaudhry, S. K. Chabra, G. A. D'Souza, D. Gupta, S. K. Katiyar, R. Kumar, B. Shah \& V. K. Vijayan. Asthma Epidemiology Study Group: A Multicentric Study on Epidemiology of Chronic Obstructive Pulmonary Disease and its Relationship with Tobacco Smoking and Environmental Tobacco Smoke Exposure. Indian J Chest Dis Allied Sci, Vol.48, No.1, pp.23-29. 2006.

[21] E. Petridou, X. Zavitsanos, N. Desspris, C. Grangakis, M. Mandyla, S. Dox-iadis \& D. Trichipoulos. Adolescents in High-risk Trajectory: Clustering of Risky Behaviour and the Origins of Socioeconomic Health Differentials. Prev Med, Vol.26, No.2, pp.215-219. 1997.

[22] Teen Smoking. Causes of Teenage Smoking, 2013, online available from

http://www.teensmoking.us/content/causes-of-teenage-smoki ng.html

[23] U.S. Department of Health and Human Services. The Health Consequences of Smoking - 50 Years of Progress: A Report of the Surgeon General. Atlanta: U.S. Department of Health and Human Services, Centers for Disease Control and Prevention, National Center for Chronic Disease Prevention and Health Promotion, Office on Smoking and Health. 2014, online available from

http://www.cdc.gov/tobacco/data statistics/sgr/50th-annivers ary/index.htm

[24] A. Landman, P. M. Ling \& S. A. Glantz. Tobacco Industry Youth Smoking Prevention Programs: Protecting the Industry and Hurting Tobacco Control, American Journal of Public Health, Vol. 92, No. 6, pp. 917-930, 2002. doi:10.2105/AJPH.92.6.917. PMC 1447482.PMID 12036777 .

[25] Kidshealth.org. Kids and Smoking. 2013, online available from http://kidshealth.org/parent/positive/talk/smoking.html.

[26] U.S. Department of Health and Human Services (USDHHS). Reducing Tobacco Use: A Report of the Surgeon General. Atlanta, GA: Public Health Service, Centers for Disease Control and Prevention, National Center for Chronic Disease Prevention and Health Promotion, Office on Smoking and Health. USDHHS. 2000.

[27] E. Schreiner. Causes for Teenage Smoking. 2013, online available from

http://motherhood.modernmom.com/causes-teenage-smokin g-4464.html

[28] Mayo Foundation for Medical Education and Research. Teen Smoking: 10 Ways to Keep Teens Smoke-Free. 2012, online available from

http://www.mayoclinic.org/healthy-living/tween-and-teen-he alth/in-depth/teen-smoking/art-20047069

[29] A. S. Abdullah, P. Driezen, A. C. K. Quah, N. Nargis \& G. T. Fong. Predictors of Smoking Cessation Behaviour among Bangladeshi Adults: Findings from ITC Bangladesh Survey. Tobacco Induced Diseases Vol.13 No.23. 2015. Doi: 10.1186/s12971-015-0050-y.

[30] M. N. Islam. An Introduction to Sampling Methods. Book
World, Bangla Bazar, Dhaka, pp.494+xv. 2007.

[31] A. Hublet, D. De Bacquer, R. Valimaa, E. Godeau, H. Schmid, G. Rahav \& L. Maes. Smoking Trends among Adolescents from 1990 to 2002 in Ten European Countries and Canada. BMC Public Health, Vol.6, pp.280. 2006.

[32] GATS. Bangladesh Report. 2009, online available from http://www.who.int/tobacco/surveillance

[33] Z. A. Laghari, J. Halepota, Z. A. Palh, K. H. Lashari, N. M. Baig, S. M. Menghwar, G. M. Mastoi, T. Jabeen, J. A. Buled \& G. A. Sahito. Factors Associated with Cigarette Smoking among Male Students of Colleges of District, Hyderabad, Pakistan. International Journal of Advancements in Research \& Technology, Vol.3, No.12. December 2014.

[34] S. Mohan, P. S. Sankara \& K. R. Thankappan. Access to Pocket Money and Low Educational Performance Predict Tobacco Use among Adolescent Boys in Kerala, India. Prev Med, Vol.41, No.11, pp.685-692. 2005.

[35] G. Rachiotis, A. S. Muula, E. Rudatsikira, S. Siziya, A. Kyrlesi, K. Gourgoulianis \& C. Hadjichristodoulou. Factors Associated with Adolescent Cigarette Smoking in Greece: Results from a Cross Sectional Study (GYTS Study). BMC Public Health, Vol.8, pp.313. 2008, online available from http://www.biomedcentral.com/1471-2458/8/313

[36] E. Austoni, V. Mirone \& F. Parazzini. Smoking as a Risk Factor for Erectile Disfunction: Data from the Andrology Prevention Weeks, 2001-2002, A Study of the Italian Society of Andrology (S.I.A.), European Urology, Vol.48, No.5, pp.810-818. 2005.

[37] M. A. AI-Yousaf \& A. Karim. Prevalence of Smoking among High School Students. Saudi Med J, Vol.22, pp.872-874, 2001.

[38] L. H. Poulsen, M. Osler, C. Robert, P. Due, M. T. Damsgaard \& B. E. Holstein. Exposure to Teacher's Smoking and Adolescent Smoking Behavior: Analysis of Cross Sectional Data from Denmark. Tob Control, Vol.11, No.246-251. 2002.

[39] Factors Associated with Adolescents' Smoking Experience and Staying Tobacco Free. Cigdem Apaydin Kaya and Pemra C Unalan. Mental Health in Family Medicine, Vol.7, No.145-153. 2010.

[40] S. Rozi, Z. A. Butt \& S. Akhtar. Correlates of Cigarette Smoking among Male College Students in Karachi, Pakistan. BMC Public Health, Vol.7, No.312. 2007, doi:10.1186/1471-2458-7-312.

[41] D. N. Sinha, P. C. Gupta \& M. S. Pednekar. Tobacco Use among Students in Bihar. Indian J Public Health, Vol.48, pp.111-117. 2004

[42] Dosomething.org. 11 Facts about Teen Smoking. 2013, online available from http://www.dosomething.org/tipsandtools/

[43] Centers for Disease Control and Prevention. Tobacco Use among Middle and High School Students United States, 2011-2014. Morbidity and Mortality Weekly Report, Vol.64, No.14, pp. 381-385. 2015

[44] Gupteshwar Singh, D.N. Sinha, P.S. Sarma \& K.R. Thankappan. Prevalence and Correlates of Tobacco Use among 10-12 Year Old School Students in Patna District, Bihar, India. Indian Pediatrics, Vol.42. August17, 2005. 
[45] USDHHS. Preventing Tobacco Use among Youth and Young Adults, A Report of the Surgeon General. Atlanta: U.S. Department of Health and Human Services, Public Health Service, Centers for Disease Control and Prevention, Office on Smoking and Health. 2012.

[46] USDHHS. The Health Consequences of Smoking -50 Years of Progress: A Report of the Surgeon General, Atlanta: U.S.
Department of Health and Human Services, Centers for Disease Control and Prevention, National Center for Chronic Disease Prevention and Health Promotion, Office on Smoking and Health. 2014.

[47] Sifferlin. Causes for Teenage Smoking. 2011, online available from http://www.ask.com/question/causes-for-teenage-smoking 